\title{
The Association Between Geographic Information System-Based Neighborhood Built Environmental Factors and Accelerometer-Derived Light-Intensity Physical Activity Across the Lifespan: A Cross- Sectional Study
}

Sofie Compernolle ( $\nabla$ sofie.compernolle@ugent.be)

Research Foundation Flanders (FWO)

Lieze Mertens

Research Foundation Flanders (FWO)

Jelle Van Cauwenberg

Research Foundation Flanders (FWO)

Iris Maes

Ghent University

Delfien Van Dyck

Ghent University

\section{Research Article}

Keywords: Physical activity, physical environment, built environment, residential density, light physical activity

Posted Date: October 13th, 2021

DOl: https://doi.org/10.21203/rs.3.rs-963637/v1

License: (c) (i) This work is licensed under a Creative Commons Attribution 4.0 International License. Read Full License

Version of Record: A version of this preprint was published at PeerJ on April 8th, 2022. See the published version at https://doi.org/10.7717/peerj.13271. 


\section{Abstract}

Background. Evidence on correlates of accelerometer-derived light-intensity physical activity (LPA) is scarce. The aim of this study was to examine associations between Geographic Information System (GIS)-based neighborhood built environmental factors and accelerometer-derived LPA, and to investigate the moderating effect of age group (adolescents, adults, older adults) on these associations.

Methods. Objective data were used from three similar observational studies conducted in Ghent (Belgium) between 2007 and 2015. Accelerometer data were collected from 1652 participants, and GISbased neighborhood built environmental factors (residential density, intersection density, park density, public transport density, entropy index) were calculated using sausage buffers of $500 \mathrm{~m}$ and $1000 \mathrm{~m}$ around the home addresses of all participants. Linear mixed models were performed to estimate the associations.

Results. A small but significant association was observed between residential density ( $500 \mathrm{~m}$ buffer) and LPA in the total sample $(B=-0.002 ; S E=0.0001 ; p=0.04)$, demonstrating that every decrease of 1000 dwellings per surface buffer was associated with a two minute increase in LPA. Intersection density, park density, public transport density and entropy index were not related to LPA, and moderating effects of age group were absent.

Conclusions. The small association, in combination with other non-significant associations suggests that the neighborhood built environment, as classically measured in moderate-to-vigorous intensity physical activity research, is of limited importance for LPA. More research is needed to unravel how accelerometerderived LPA is accumulated, and to gain insight into its determinants.

\section{Background}

Physical inactivity is considered to be a major public health issue worldwide due to its contribution to a range of non-communicable diseases and premature mortality (1). Research has estimated that a lack of physical activity causes $6 \%$ of the burden of disease from coronary heart disease, $7 \%$ of type 2 diabetes, $10 \%$ of breast and colon cancer, and $9 \%$ of premature mortality, which corresponds to approximately 5.3 million deaths worldwide (2). To reduce the burden of physical inactivity, updated physical activity guidelines were proposed in 2020 by the World Health Organization (WHO). These updated guidelines emphasize that all types and intensities of physical activity count, bringing greater attention to the previously ignored light-intensity physical activities (LPA) (3). According to Ainsworth's Compendium of Physical Activities, LPA's include all activities performed at 1.6 - 3 metabolic equivalent of tasks (METs) (4). Examples of frequently performed LPA's are standing, slow walking $(\leq 3 \mathrm{~km} / \mathrm{h})$ and gardening (5).

Although often overlooked, LPA can play a key role in health promotion and disease prevention. Recent systematic reviews and meta-analyses have indicated that LPA was favorably associated with some cardiometabolic risk factors including waist circumference, triglyceride levels, insulin, and the presence of 
metabolic syndrome in different age groups. LPA was also inversely associated with all-cause mortality risk after adjustment for moderate-to-vigorous intensity physical activity (MVPA) (6-8). Results of a longitudinal cohort study among 4,840 US adults showed that those adults who performed $4 \mathrm{~h} /$ day of LPA had a $21 \%$ lower risk of mortality compared with those who did less LPA (9). Focusing on LPA might thus be important, particularly for whom the recommended $60 \mathrm{~min} /$ day (adolescents) or 150-300 min/week (adults and older adults) of MVPA are challenging to achieve (10).

Up till now, determinant studies of LPA have mainly focused on walking. Walking, which is a common form of LPA if performed slowly, is influenced by one's built environmental neighborhood (11). Concretely, systematic reviews revealed strong evidence for positive associations between neighborhood walkability, number of destinations, greenery, and aesthetically pleasing environments on the one hand, and walking on the other hand, in different age groups (11-15). However, important to note, is that the majority of these findings are based on self-reported walking data without taking into account walking speed. The proportion of slow walking in previous studies remains thus unclear. Research into objective accelerometer-derived LPA can provide useful and complementary insights.

A recent systematic review, focusing on objectively Geographic Information System (GIS)-measured built environmental factors and accelerometer-derived physical activity, showed that among the sixty included studies, only eight investigated the influence on LPA (16). Results of these few studies were also inconsistent (17). For example, in the cross-sectional study of Chen et al. no significant associations were found between neighborhood walkability attributes and LPA in 124 older Taiwanese adults (18), whereas in the study of Van Holle et al., and the study of Goncalvez et al., walkability and residential density were inversely associated with LPA in a sample of 438 Belgian older adults, and 305 Brazilian adults, respectively $(19,20)$. Next to the potential moderating role of geographical location, the detected inconsistencies might also be attributed to age-related differences in the studied samples. Neighborhood built environmental factors might be of greater importance to adolescents' and older adults' LPA, as these population subgroups generally spend more time in their neighborhood than adults due to mobility limitations. For example, the majority of adolescents cannot independently travel by car due to the lack of a driver license, and older adults often cease driving due to aging-related health issues (21-23). To our knowledge, no studies have been conducted to examine the moderating role of age group on the associations between GIS-based neighborhood built environmental factors and accelerometer-derived LPA.

To add to the limited knowledge on the determinants of objectively measured LPA, the aims of the current study were 1) to investigate the associations between GIS-based neighborhood built environmental factors and accelerometer-derived LPA, and 2) to examine the moderating effect of age group (adolescents, adults, older adults) on these associations. It was hypothesized that stronger associations will be detected between neighborhood built environmental factors and LPA in adolescents and older adults, compared to young and middle-aged adults.

\section{Methods}




\section{Study design}

Data from three observational studies with a similar methodology were combined to examine associations between neighborhood built environmental factors and LPA across the lifespan. All three studies were conducted in Ghent, Flanders. The Belgian Environmental Physical Activity Study (BEPAS) collected data from adults (20-65 years) between May 2007 and September 2008 (24), and the BEPAS Seniors collected data from older adults ( $\geq 65$ years) between October 2010 and September 2012 (25). The Belgian International Physical activity and the Environment Network (IPEN) study in Adolescents collected data from adolescents (11-17 years) between September 2014 and December 2015 (26). All three studies were approved by the Ethics Committee of the Ghent University Hospital and all participants provided written informed consent.

\section{Participants and procedure}

Stratified cluster sampling based on walkability (low vs high) and neighborhood socio-economic status (SES) (low vs high) was used to select neighborhoods (i.e. 1 to 5 adjacent statistical sectors) in Ghent (i.e. city in Flanders, Belgium) for the three observational studies $(24,25)$. A total of 24 neighborhoods were selected from four neighborhood types (i.e. high walkable/high SES; high walkable/low SES; low walkable/high SES; low walkable/low SES) to recruit adult participants for BEPAS (24). Subsequently, 250 adults of each neighborhood were randomly sampled by the Public Service of Ghent. For BEPAS Seniors, 20 out of these 24 neighborhoods were selected to randomly sample 1750 older adults stratified by age and gender (25). For IPEN Adolescents, 442 adolescents were randomly sampled from the 24 neighborhoods that were initially selected for BEPAS. Next to the recruitment by residential address, adolescents were also recruited from schools located in the 24 neighborhoods (26). Selected adolescents, adults and older adults received an invitation letter with the announcement of a home or school visit of a trained researcher within the next days. Candidates were considered to be eligible for the study if they lived in a private dwelling, were able to walk a couple of hundred meters without assistance and were able to fill out a Dutch questionnaire. The recruitment process resulted in a sample of 373 adolescents, 1200 adults, and 508 older adults who were found at home/school, met the inclusion criteria, and willing to participate. All participants filled in a questionnaire on sociodemographic and psychosocial factors, and physical activity. Additionally, one of the parents of each adolescent participant also completed a brief socio-demographic questionnaire. By the end of the first home/school visit, participants received an Actigraph accelerometer, which they were instructed to wear for seven consecutive days. After seven days, a second home/school visit took place to collect the Actigraph accelerometers.

\section{Measures}

\section{Outcome variable: $L P A$}

LPA was objectively assessed with ActiGraph 7164, GT1M, GT3X and GT3X + accelerometers (ActiGraph, Fort Walton Beach, FL, USA), which are valid and reliable tools to measure PA levels in different age groups (27-30). Accelerometers were attached using an adjustable elastic waist belt above the right hip 
for seven consecutive days. Participants were asked to only remove the accelerometer while sleeping, and for water-based activities, such as swimming or bathing. Accelerometer counts were collected using 60second epochs. Non-wear time, which was defined as $\geq 60 \mathrm{~min}$ of consecutive zeros, was removed (31), and participants with less than five valid days of data (i.e. at least 10 wearing hours) were excluded from the analysis (32). According to the recommended cut points of Freedson (33), and Evenson (34), 101 through 1,951 counts/minute were considered LPA in adults and older adults, and 101 through 2296 counts/minutes were considered LPA in adolescents. The complete accelerometer data processing was performed using Actilife software version 6.

\section{Predictor variables: GIS-based neighborhood built environmental factors}

GIS-based neighborhood built environmental factors were calculated using sausage buffers of $500 \mathrm{~m}$

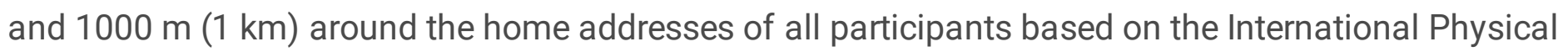
Environmental Network (IPEN) guidelines (35). Sausage buffers are preferred over the more traditional Euclidian buffers, as sausage buffers are directly based on the road networks used to travel (36). Five GIS-based neighborhood built environmental factors were included in the current study: residential density, intersection density, park density, public transport density, and entropy. Residential density was defined as the ratio between the number of residences fully or partially in the buffer and the total buffer area. Intersection density was described as the ratio between the number of three- or more-way intersections and the total buffer area. Park density was the ratio between the number of parks fully or partially in the buffer and the total buffer area, and public transport density was calculated by dividing the number of public transport stops (i.e. bus, tram, train stops) by the total buffer area. Finally, the entropy index was a measure of land use mix which took into account the relative percentage of six land use types (i.e. residential, commercial, institutional, entertainment, food and private/public recreation parcels) within the total buffer area (37).

Potential confounding/moderating variables: socio-demographic factors, valid days, and wear time

Age group, gender, educational level (primary, secondary, or tertiary), neighborhood SES, number of valid days, and wear time were selected a priori as potential confounding/moderating variables. Sociodemographic confounding variables were self-reported by the participants (or their parents) during the first home/school visit. Since adolescents were still studying, highest achieved educational level of the parent who filled in the questionnaire was included in the analyses as a proxy for their SES.

Neighborhood SES was based on Belgian census income data from the National Institute of Statistics. Number of valid days and wear time were extracted from the accelerometer data.

\section{Statistical analyses}

Descriptive statistics of participants' characteristics were calculated for the total sample and the three age groups (adolescents, adults and older adults) separately. Means and standard deviations were provided for normally distributed continuous variables, medians and interquartile ranges for skewed continuous variables, and percentages for discrete variables. Linear mixed models were performed using 
the Imer() function of the Ime4 package in $\mathrm{R}(\mathrm{v}$ 4.1.0) to account for the nested structure of the data (i.e. individuals were nested within neighborhoods) while examining the associations between GIS-based neighborhood built environmental factors and accelerometer-derived LPA (38). Firstly, a random intercept null model was fitted to estimate the variance in LPA explained at the neighborhood level. The intraclass cluster coefficient (ICC) was calculated from this model to estimate the proportion of total variance in LPA that could be attributed to neighborhood factors. Secondly, single-predictor models were run with each potential confounding variable (i.e. age group, gender, educational level, neighborhood SES, number of valid days, and wear time), and each GIS-based neighborhood built environmental factor (i.e. residential density, intersection density, park density, public transport density, and entropy) separately. Thirdly, multiple-predictor models were fitted including the significant confounding variables from the previous step, and the GIS-based built environmental neighborhood factors. Finally, the multiple-predictor models were extended with an interaction term (i.e. age group*GIS-based neighborhood built environmental factor) to investigate the potential moderating role of age group. A likelihood ratio test was used to test the significance of the interaction terms by comparing models with and without interaction terms. All single- and multiple-predictor models were run separately for the environmental variables measured in a $500 \mathrm{~m}$ and $1 \mathrm{~km}$ sausage buffer. All analyses were performed in R ( $\mathrm{v} 4.1 .0)$ and the alpha level was set 0.05 .

\section{Results}

\section{Descriptive statistics of the participants}

Participants with invalid accelerometer data (i.e. less than five days with at least $10 \mathrm{~h}$ of wearing time) $(n=323)$ or GIS-data $(n=106)$ were excluded from the study. This resulted in a total sample of 1652 participants, of which 150 adolescents, 1059 adults and 443 older adults. Descriptive statistics of the participants are presented in Table 1. The mean age of the sample was $48.8( \pm 20.4)$ years, and about half of the sample was female. The sample spent on average $304.6( \pm 96.3) \mathrm{min}$ in LPA per day, ranging from $226.9( \pm 46.8) \mathrm{min} /$ day for adolescents to $335.2( \pm 92.2) \mathrm{min} /$ day for adults.

Table 1: Descriptive statistics of the participants 


\section{Total sample Adolescents Adults Older adults \\ $(n=1652) \quad(n=150) \quad(n=1059) \quad(n=443)$}

\section{Socio-demographic variables}

Age, in years, mean (SD), range

$48.8(20.4)$,

$11-92$

13.6 (1.3),

$11-17$

$42.9(12.4)$

$18-64$

74.1 (6.2),

65-92

Gender, \% female

52.4

53.7

51.6

54.1

Educational level

\begin{tabular}{|c|c|c|c|c|}
\hline$\%$ primary & 9.9 & 4.8 & 4.2 & 25.2 \\
\hline$\%$ secondary & 32.8 & 20.0 & 33.1 & 36.4 \\
\hline$\%$ tertiary & 57.3 & 75.2 & 62.7 & 38.4 \\
\hline \multicolumn{5}{|l|}{ Accelerometer-derived variables } \\
\hline LPA, min/day, mean (SD) & $304.6(96.3)$ & $226.9(46.8)$ & $335.2(92.2)$ & $257.9(84.3)$ \\
\hline LPA, \% of the day, mean (SD) ${ }^{a}$ & $35.0(10.5)$ & $27.6(9.2)$ & $38.1(10.3)$ & $30.1(5.5)$ \\
\hline Wear time & $869.4(83.8)$ & $821.5(54.0)$ & $882.3(84.2)$ & $854.8(83.0)$ \\
\hline Valid days & $6.8(0.8)$ & $7.4(1.2)$ & $6.8(0.8)$ & $6.8(0.5)$ \\
\hline
\end{tabular}

GIS-based neighborhood built environmental variables

\begin{tabular}{|c|c|c|c|c|}
\hline $\begin{array}{l}\text { Residential density } 500 \mathrm{~m} \text {, mean } \\
(\mathrm{SD})^{\mathrm{b}}\end{array}$ & $\begin{array}{l}4770.5 \\
(3226.2)\end{array}$ & $\begin{array}{l}4271.9 \\
(3150.4)\end{array}$ & $\begin{array}{l}4795.6 \\
(3227.7)\end{array}$ & $\begin{array}{l}4879.2 \\
(3240.1)\end{array}$ \\
\hline $\begin{array}{l}\text { Residential density } 1000 \text { m, mean } \\
(S D)^{c}\end{array}$ & $\begin{array}{l}4357.4 \\
(2987.6)\end{array}$ & $\begin{array}{l}3875.4 \\
(2669.5)\end{array}$ & $\begin{array}{l}4387.7 \\
(3018.7)\end{array}$ & $\begin{array}{l}4448.3 \\
(3006.0)\end{array}$ \\
\hline $\begin{array}{l}\text { Intersection density } 500 \text { m, mean } \\
(S D)^{d}\end{array}$ & $160.5(68.3)$ & $155.0(63.0)$ & $159.9(68.4)$ & $163.7(69.6)$ \\
\hline $\begin{array}{l}\text { Intersection density } 1000 \text { m, mean } \\
(S D)^{\mathrm{e}}\end{array}$ & $157.2(65.0)$ & $148.7(56.6)$ & $158.1(65.6)$ & $157.8(66.1)$ \\
\hline $\begin{array}{l}\text { Park density } 500 \text { m, median (Q1- } \\
\text { Q3) }{ }^{f}\end{array}$ & $8.0(3.7-12.6)$ & $\begin{array}{l}6.6(0.0- \\
13.3)\end{array}$ & $7.6(0.0-11.5)$ & $\begin{array}{l}9.9(5.5- \\
15.8)\end{array}$ \\
\hline $\begin{array}{l}\text { Park density } 1000 \text { m, median (Q1- } \\
\text { Q3) }\end{array}$ & $7.2(3.9-11.4)$ & $\begin{array}{l}7.6(3.7- \\
12.5)\end{array}$ & $6.9(3.8-10.8)$ & $\begin{array}{l}8.0(4.5- \\
13.3)\end{array}$ \\
\hline $\begin{array}{l}\text { Public transport density } 500 \text { m, } \\
\text { mean }(S D)^{\mathrm{h}}\end{array}$ & 33.7 (20.0) & $29.8(19.8)$ & $34.4(20.0)$ & $33.6(20.0)$ \\
\hline $\begin{array}{l}\text { Public transport density } 1000 \text { m, } \\
\text { mean (SD) }\end{array}$ & $32.9(13.7)$ & $29.2(14.4)$ & $33.1(13.6)$ & $33.5(13.4)$ \\
\hline
\end{tabular}




\begin{tabular}{|lllll|} 
Entropy index $500 \mathrm{~m}$, mean (SD) $)^{\mathrm{j}}$ & $0.5(0.2)$ & $0.4(0.2)$ & $0.5(0.2)$ & $0.5(0.2)$ \\
\hline Entropy index $1000 \mathrm{~m}$, mean (SD) & $0.5(0.2)$ & $0.5(0.1)$ & $0.5(0.2)$ & $0.6(0.2)$
\end{tabular}

$\mathrm{SD}=$ Standard deviation; min=minutes; $\mathrm{LPA}=$ light-intensity physical activity; ${ }^{\mathrm{a}} \%$ of wear time; ${ }^{\mathrm{b}}$ number of dwellings per surface buffer $500 \mathrm{~m} ;{ }^{c}$ number of dwellings per surface buffer $1 \mathrm{~km}$; ${ }^{d}$ number of intersections per surface buffer $500 \mathrm{~m} ;{ }^{e}$ number of intersections per surface buffer $1 \mathrm{~km} ;{ }^{f}$ number of public parks of all sizes per surface buffer $500 \mathrm{~m} ;{ }^{9}$ number of public parks of all sizes per surface buffer $1 \mathrm{~km}$; ${ }^{\mathrm{h}}$ number of public transportation stops of any kind per surface buffer $500 \mathrm{~m}$; ${ }^{\mathrm{i}}$ number of public transportation stops of any kind per surface buffer $1 \mathrm{~km} ;{ }^{j}$ range from 0 (=perfect homogenous land use) to 1 (=perfect heterogeneous land use.

\section{Associations between GIS-based neighborhood built environmental factors and accelerometer-derived LPA}

The ICC of the random intercept null model was 0.123 , indicating that $12.3 \%$ of the variance in LPA can be attributed to the neighborhood level. Table 2 presents the results of the single- and multiple-predictor mixed effects regression models. Results of the multiple-predictor model for the $500 \mathrm{~m}$ sausage buffer showed that residential density is significantly related to LPA. Concretely, every decrease of 1000 dwellings per $500 \mathrm{~m}$ surface buffer was associated with a two minute increase in LPA. None of the other GIS-based neighborhood built environmental factors were related to LPA in the model with the $500 \mathrm{~m}$ sausage buffer. Results of the multiple-predictor model for the $1000 \mathrm{~m}$ buffer showed that none of the included GIS-based built environmental factors (i.e. residential density, intersection density, park density, public transport density and entropy) were significantly associated with LPA.

Table 2: Associations between GIS-based neighborhood built environmental factors and accelerometerderived LPA 
Single-predictor models Multiple-predictor models - LPA

- LPA

Buffer $500 \mathrm{~m}$

Buffer $1000 \mathrm{~m}$

$\begin{array}{llllll}B(S E) & \text { p } & \text { B (SE) } & \text { p } & \text { B (SE) } & \text { p }\end{array}$

\section{Socio-demographic variables}

Adults (ref. adolescents)

$110.5(8.1)$

$\hat{0} .001$

$88.8(7.4) \quad \hat{0} 001$

$89.3(7.5) \quad \hat{0} 001$

Older adults (ref.

adolescents)

$32.4(8.8)$

$\hat{0} .001$

$15.0(8.1)$

$0.06 \quad 16.4(8.2)$

0.05

Women (ref. men)

$18.48(4.6)$

<. 001

$26.3(4.1)$

0.001

$26.4(4.1)$

$<$

Secondary (ref. primary)

$37.5(8.4)$

0.001

4.7 (7.5)

0.54

$5.7(7.5)$

0.45

Tertiary (ref. primary)

$24.6(8.3)$

0.003

- $18.1(7.5)$

$0.02-16.1(7.5)$

0.03

Neighborhood SES

High (ref. low)

$1.27(11.59)$

0.913

Accelerometer-derived variables

Wear time (min/day)

$0.36(0.02$

<. 001

$0.3(0.02)$

<. 001

$0.3(0.02)$

$<$

Valid days

$4.6(2.9)$

0.11

GIS-based neighborhood built environmental variables

\begin{tabular}{lllllll}
$\begin{array}{l}\text { Residential density } 500 \\
\mathrm{~m}^{\mathrm{a}}\end{array}$ & $\begin{array}{l}-0.001 \\
(0.001)\end{array}$ & 0.30 & $\begin{array}{c}-\mathbf{0 . 0 0 2} \\
\mathbf{( 0 . 0 0 1 )}\end{array}$ & $\mathbf{0 . 0 4}$ & - & - \\
\hline $\begin{array}{l}\text { Residential density 1000 } \\
\mathrm{m}^{\mathrm{b}}\end{array}$ & $\begin{array}{l}-0.001 \\
(0.001)\end{array}$ & 0.24 & - & - & $\begin{array}{l}-0.003 \\
(0.002)\end{array}$ & 0.09 \\
\hline $\begin{array}{l}\text { Intersection density 500 } \\
\mathrm{m}^{\mathrm{c}}\end{array}$ & $-0.05(0.05)$ & 0.28 & $\begin{array}{l}-0.03 \\
(0.05)\end{array}$ & 0.58 & - & - \\
\hline $\begin{array}{l}\text { Intersection density 1000 } \\
\mathrm{m}^{\mathrm{d}}\end{array}$ & $\begin{array}{l}-0.0007 \\
(0.05)\end{array}$ & 0.99 & - & - & $0.05(0.07)$ & 0.51
\end{tabular}

Park density $500 \mathrm{~m}^{\mathrm{e}}$

$-0.37(0.29)$

0.21

$-0.04$

$(0.24)$

Park density $1000 \mathrm{~m}^{f}$

$-1.33(0.61) \quad 0.03$

$-0.34$

$(0.52)$

0.51

Public transport density $500 \mathrm{~m}^{\mathrm{g}}$

$-0.06(0.14) \quad 0.67$

$-0.11$

(0.12)

0.38 


\begin{tabular}{|lllllll|}
\hline $\begin{array}{l}\text { Public transport density } \\
1000 \mathrm{~m}^{\mathrm{h}}\end{array}$ & $-0.15(0.23)$ & 0.53 & - & - & $0.03(0.02)$ & 0.90 \\
\hline Entropy index $500 \mathrm{~m}^{\mathrm{i}}$ & $-22.0(13.6)$ & 0.11 & $\begin{array}{l}-13.5 \\
(13.8)\end{array}$ & 0.33 & - & - \\
\hline Entropy index $1000 \mathrm{~m}^{\mathrm{i}}$ & $-22.2(17.4)$ & 0.20 & - & - & -34.7 & 0.08 \\
\hline
\end{tabular}

$D=S t a n d a r d$ deviation; min=minutes; LPA=light-intensity physical activity; ${ }^{a}$ number of dwellings per surface buffer $500 \mathrm{~m} ;{ }^{b}$ number of dwellings per surface buffer $1 \mathrm{~km} ;{ }^{c}$ number of intersections per surface buffer $500 \mathrm{~m} ;{ }^{d}$ number of intersections per surface buffer $1 \mathrm{~km}$; ${ }^{e}$ number of public parks of all sizes per surface buffer $500 \mathrm{~m} ;{ }^{f}$ number of public parks of all sizes per surface buffer $1 \mathrm{~km} ;{ }^{9}$ number of public transportation stops of any kind per surface buffer $500 \mathrm{~m} ;{ }^{\text {h }}$ number of public transportation stops of any kind per surface buffer $1 \mathrm{~km}$; ${ }^{i}$ range from 0 (=perfect homogenous land use) to 1 (=perfect heterogeneous land use.

\section{Moderating role of age group on the associations between GIS-based neighborhood built environmental factors and accelerometer-derived LPA}

Table 3 lists the results of the likelihood ratio test comparing the multiple-predictor model of accelerometer-derived LPA with and without interaction terms (GIS-based built environmental factors * age group). Results showed that none of the interaction effects were significant, indicating that the association between GIS-based built environmental factors and LPA did not differ depending on age group.

Table 3: Moderating role of age group on the association between GIS-based neighborhood built environmental factors and accelerometer-derived LPA 


\begin{tabular}{|c|c|c|c|}
\hline Buffer size & Built environmental factor & $\begin{array}{l}\mathrm{Chi}^{2}(\mathrm{df}) \text { for interaction effect } \\
\text { age group * built environmental factor }\end{array}$ & $\mathbf{p}$ \\
\hline \multirow[t]{5}{*}{$500 m$} & Residential density & $2.05(2)$ & 0.36 \\
\hline & Intersection density & $0.04(2)$ & 0.98 \\
\hline & Park density & $1.89(2)$ & 0.39 \\
\hline & Public transport density & $2.29(2)$ & 0.32 \\
\hline & Entropy index & $0.89(2)$ & 0.64 \\
\hline \multirow[t]{5}{*}{$1 \mathrm{~km}$} & Residential density & $1.70(2)$ & 0.43 \\
\hline & Intersection density & $0.05(2)$ & 0.97 \\
\hline & Park density & $0.43(2)$ & 0.81 \\
\hline & Public transport density & $0.50(2)$ & 0.78 \\
\hline & Entropy index & $0.92(2)$ & 0.63 \\
\hline
\end{tabular}

\section{Discussion}

This study is the first to investigate the association between GIS-based neighborhood built environmental factors and accelerometer-derived LPA in different age groups. The results showed only one significant association, namely that residential density ( $500 \mathrm{~m}$ buffer) was inversely associated with LPA in the total sample. This finding is in line the results of previous LPA studies, $(19,20)$, suggesting that residents of dense neighborhoods are less likely to engage in LPA. Important to note is, however, that the effect size of the observed association is rather limited, and that the clinical relevance might thus be questioned.

At first sight, it seems that the current findings contrast with previous evidence regarding built environmental determinants of MVPA, showing that neighborhoods with high residential density were positively associated with MVPA $(24,39,40)$. However, LPA and MVPA are interrelated as they both occur - together with sleep and sedentary behavior - within a finite 24-hour window (41). Less time in one behavior might thus lead to more time in another behavior. Or, concretely, it might be that residents of more dense neighborhoods might partly replace their LPA by MVPA. More research including the full 24hour activity cycle is needed in order to confirm the previous hypothesis, and to decide upon the most physical activity-friendly neighborhood environment.

Furthermore, it is important to shed light on the behaviors that are included in accelerometer-derived LPA to fully understand the inverse association. Although the interpretation of LPA is still not entirely clear, it seems that activities, such as gardening, cooking and cleaning belong to LPA (5). As residents of 
neighborhoods with low residential density are more likely to live in large houses, with large gardens, this could possibly explain the inverse association (20). Next to the behaviors that are classified as LPA, additional insight into the percentage of LPA that is spent walking in one's neighborhood could help to identify potential determinants. Given the limited number of observed associations between neighborhood built environmental factors and LPA, it is suspected that walking slowly in the neighborhood makes only a small contribution to the total time spent in LPA. Studies combining GPS and accelerometer data are recommended to map the proportion of time in LPA spent in- and outdoors.

Contrary to our hypothesis, no stronger associations were observed between environmental neighborhood factors and LPA in adolescents and older adults, compared to young and middle-aged adults. Again, this could be explained by the fact that walking slowly in one's neighborhood represents only a small part of total accelerometer-derived LPA. If future research confirms that LPA occurs only to a limited extent in one's neighborhood, examining the role of the home, school and work environment will, just as with sedentary behavior, be more relevant to detect determinants than investigating the influence of neighborhood factors (42). Next to the home, school and work environment, psychological and social environmental factors were also understudied, and deserve more attention in future LPA studies.

This study has several strengths. To our knowledge, no previous studies have investigated the associations between GIS-based neighborhood built environmental factors and accelerometer-derived LPA in three different age groups. However, including different age groups is important in environmental research, as recommendations to policy makers and urban planners can only be formulated if an environment is supportive for all age groups. Secondly, GIS-based measures were used to assess neighborhood built environmental factors, and accelerometers were applied to estimate LPA. By relying solely on objective measures, recall and/or social desirability biases were eliminated, and accuracy of estimations was improved. Lastly, a sample of more than 1600 people was included in the current study, which guarantees sufficient power to detect potential associations. Limitations of the current study include firstly the lack of context-specific LPA information. Information on the context in which LPA was performed would have been helpful to interpret the results, and to formulate recommendations. Secondly, the cross-sectional design did not allow us to address the direction of causality. A longitudinal design would be recommended to understand the residential density-LPA association. Thirdly, the overrepresentation of highly educated persons, and adults in the sample limits the representativeness and generalizability. A more heterogeneous sample with regard to highest obtained educational level, and age group, would have improved the external validity of the results. Finally, the lack of universal consensus on accelerometer cut-points, especially in older adults, might have influenced the results of the current study. Time in LPA may have been overestimated for older adults with low fitness (10).

\section{Conclusion}

The current results suggest that the contribution of the objectively-measured physical neighborhood environment is limited in explaining accelerometer-derived LPA in all age groups. Only residential density (500 $\mathrm{m}$ buffer) was related to LPA. The small, but significant inverse association suggested that residents 
from dense neighborhoods are less likely to engage in LPA compared to residents from less dense neighborhoods. More research is needed into the neighborhood influence on the full 24-hour activity cycle, and into the concept of accelerometer-derived LPA to fully understand the findings of the current study.

\section{Abbreviations}

Light-intensity physical activity: LPA

Geographic Information System: GIS

World Health Organization: WHO

Metabolic equivalent of tasks: METs

Moderate-to-vigorous intensity physical activity: MVPA

Belgian Environmental Physical Activity Study: BEPAS

International Physical activity and the Environment Network: IPEN

Socio-economic status: SES

Intraclass cluster coefficient: ICC

\section{Declarations}

\section{Ethics approval and consent to participate}

All three studies were approved by the Ethics Committee of the Ghent University Hospital (andere nummers? B670201423000) and all participants provided written informed consent.

\section{Consent for publication}

Not applicable.

\section{Availability of data and materials}

The datasets used and/or analysed during the current study are available from the corresponding author on reasonable request.

\section{Competing interests}

The authors have no competing interests to declare.

\section{Funding}


This research was supported by the Research Foundation Flanders (FWO) B/13018/01. Sofie Compernolle (FWO20/PDJ/088), Lieze Mertens (FW017/PDO/140) and Jelle Van Cauwenberg (FWO $1211117 \mathrm{~N}$ ) are supported by a postdoctoral fellowship of the Research Foundation Flanders.

\section{Authors' contributions}

SC conceived of the idea for the manuscript. DVD and JVC coordinated the data collection. SC conducted the statistical analyses, interpreted the data and drafted the manuscript. All authors read, provided feedback, and approved the final submitted version of the manuscript.

\section{Acknowledgements}

The authors would like to thank the master students who contributed to the data collection, and the participants of the three studies (BEPAS Adults, BEPAS Seniors and IPEN adolescents).

\section{References}

1. Katzmarzyk PT, Friedenreich C, Shiroma EJ, Lee I-M. Physical inactivity and non-communicable disease burden in low-income, middle-income and high-income countries. British journal of sports medicine. 2021.

2. Lee I-M, Shiroma EJ, Lobelo F, Puska P, Blair SN, Katzmarzyk PT, et al. Effect of physical inactivity on major non-communicable diseases worldwide: an analysis of burden of disease and life expectancy. The lancet. 2012;380(9838):219-29.

3. van der Ploeg HP, Bull FC. Invest in physical activity to protect and promote health: the 2020 WHO guidelines on physical activity and sedentary behaviour. Springer; 2020.

4. Ainsworth BE, Haskell WL, Whitt MC, Irwin ML, Swartz AM, Strath SJ, et al. Compendium of physical activities: an update of activity codes and MET intensities. Medicine and science in sports and exercise. 2000;32(9; SUPP/1):S498-S504.

5. Mendes MdA, Da Silva I, Ramires V, Reichert F, Martins R, Ferreira R, et al. Metabolic equivalent of task (METs) thresholds as an indicator of physical activity intensity. PloS one. 2018;13(7):e0200701.

6. Amagasa S, Machida M, Fukushima N, Kikuchi H, Takamiya T, Odagiri Y, et al. Is objectively measured light-intensity physical activity associated with health outcomes after adjustment for moderate-to-vigorous physical activity in adults? A systematic review. International Journal of Behavioral Nutrition and Physical Activity. 2018;15(1):1-13.

7. Ku PW, Hamer M, Liao Y, Hsueh MC, Chen LJ. Device-measured light-intensity physical activity and mortality: A meta-analysis. Scandinavian journal of medicine \& science in sports. 2020;30(1):13-24.

8. Fuezeki E, Engeroff T, Banzer W. Health benefits of light-intensity physical activity: a systematic review of accelerometer data of the National Health and Nutrition Examination Survey (NHANES). Sports Medicine. 2017;47(9):1769-93. 
9. Matthews CE, Keadle SK, Troiano RP, Kahle L, Koster A, Brychta R, et al. Accelerometer-measured dose-response for physical activity, sedentary time, and mortality in US adults. The American journal of clinical nutrition. 2016;104(5):1424-32.

10. del Pozo Cruz B, Biddle SJ, Gardiner PA, Ding D. Light-Intensity Physical Activity and Life Expectancy: National Health and Nutrition Survey. American journal of preventive medicine. 2021.

11. Saelens BE, Handy SL. Built environment correlates of walking: a review. Medicine and science in sports and exercise. 2008;40(7 Suppl):S550.

12. Barnett DW, Barnett A, Nathan A, Van Cauwenberg J, Cerin E. Built environmental correlates of older adults' total physical activity and walking: a systematic review and meta-analysis. International journal of behavioral nutrition and physical activity. 2017;14(1):1-24.

13. Smith M, Hosking J, Woodward A, Witten K, MacMillan A, Field A, et al. Systematic literature review of built environment effects on physical activity and active transport-an update and new findings on health equity. International journal of behavioral nutrition and physical activity. 2017;14(1):1-27.

14. Wang Y, Chau CK, Ng W, Leung T. A review on the effects of physical built environment attributes on enhancing walking and cycling activity levels within residential neighborhoods. Cities. 2016;50:1-15.

15. McCormack GR, Shiell A. In search of causality: a systematic review of the relationship between the built environment and physical activity among adults. International journal of behavioral nutrition and physical activity. 2011;8(1):1-11.

16. Yi L, Wilson JP, Mason TB, Habre R, Wang S, Dunton GF. Methodologies for assessing contextual exposure to the built environment in physical activity studies: A systematic review. Health \& place. 2019;60:102226.

17. Whitaker KM, Xiao Q, Gabriel KP, Larsen PG, Jacobs Jr DR, Sidney S, et al. Perceived and objective characteristics of the neighborhood environment are associated with accelerometer-measured sedentary time and physical activity, the CARDIA Study. Preventive medicine. 2019;123:242-9.

18. Chen B-I, Hsueh M-C, Rutherford R, Park J-H, Liao Y. The associations between neighborhood walkability attributes and objectively measured physical activity in older adults. PloS one. 2019;14(9):e0222268.

19. Gonçalves PB, Hallal PC, Hino AAF, Reis RS. Individual and environmental correlates of objectively measured physical activity and sedentary time in adults from Curitiba, Brazil. International journal of public health. 2017;62(7):831-40.

20. Van Holle V, Van Cauwenberg J, Van Dyck D, Deforche B, Van de Weghe N, De Bourdeaudhuij I. Relationship between neighborhood walkability and older adults' physical activity: results from the Belgian Environmental Physical Activity Study in Seniors (BEPAS Seniors). International journal of behavioral nutrition and physical activity. 2014;11(1):1-9.

21. Beard JR, Blaney S, Cerda M, Frye V, Lovasi GS, Ompad D, et al. Neighborhood characteristics and disability in older adults. Journals of Gerontology: Series B. 2009;64(2):252-7.

22. Oyeyemi AL, Kolo SM, Oyeyemi AY, Omotara BA. Neighborhood environmental factors are related to health-enhancing physical activity and walking among community dwelling older adults in Nigeria. 
Physiotherapy theory and practice. 2019;35(3):288-97.

23. Vilhjalmsdottir A, Gardarsdottir RB, Bernburg JG, Sigfusdottir ID. Neighborhood income inequality, social capital and emotional distress among adolescents: A population-based study. Journal of adolescence. 2016;51:92-102.

24. Van Dyck D, Cardon G, Deforche B, Sallis JF, Owen N, De Bourdeaudhuij I. Neighborhood SES and walkability are related to physical activity behavior in Belgian adults. Preventive medicine. 2010;50:S74-S9.

25. Van Holle V, Van Cauwenberg J, Van Dyck D, Deforche B, Van de Weghe N, De Bourdeaudhuij I. Relationship between neighborhood walkability and older adults' physical activity: results from the Belgian Environmental Physical Activity Study in Seniors (BEPAS Seniors). International journal of behavioral nutrition and physical activity. 2014;11(1):110.

26. Cain KL, Salmon J, Conway TL, Cerin E, Hinckson E, Mitáš J, et al. International Physical Activity and Built Environment Study of adolescents: IPEN Adolescent design, protocol and measures. BMJ open. 2021;11(1):e046636.

27. Aadland E, Ylvisåker E. Reliability of the Actigraph GT3X+ accelerometer in adults under free-living conditions. PloS one. 2015;10(8):e0134606.

28. Vanhelst J, Mikulovic J, Bui-Xuan G, Dieu O, Blondeau T, Fardy P, et al. Comparison of two ActiGraph accelerometer generations in the assessment of physical activity in free living conditions. BMC research notes. 2012;5(1):1-4.

29. Colbert LH, Matthews CE, Havighurst TC, Kim K, Schoeller DA. Comparative validity of physical activity measures in older adults. Medicine and science in sports and exercise. 2011;43(5):867.

30. Vanhelst J, Béghin L, Duhamel A, Bergman P, Sjöström M, Gottrand F. Comparison of uniaxial and triaxial accelerometry in the assessment of physical activity among adolescents under free-living conditions: the HELENA study. BMC medical research methodology. 2012;12(1):1-6.

31. Choi L, Ward SC, Schnelle JF, Buchowski MS. Assessment of wear/nonwear time classification algorithms for triaxial accelerometer. Medicine and science in sports and exercise. 2012;44(10):2009.

32. Grimm EK, Swartz AM, Hart T, Miller NE, Strath SJ. Comparison of the IPAQ-Short Form and accelerometry predictions of physical activity in older adults. Journal of aging and physical activity. 2012;20(1):64-79.

33. Freedson PS, Melanson E, Sirard J. Calibration of the computer science and applications, inc. accelerometer. Medicine and science in sports and exercise. 1998;30(5):777-81.

34. Evenson KR, Catellier DJ, Gill K, Ondrak KS, McMurray RG. Calibration of two objective measures of physical activity for children. Journal of sports sciences. 2008;26(14):1557-65.

35. Adams MA, Frank LD, Schipperijn J, Smith G, Chapman J, Christiansen LB, et al. International variation in neighborhood walkability, transit, and recreation environments using geographic information systems: the IPEN adult study. International journal of health geographics. 2014;13(1):117. 
36. Forsyth A, Van Riper D, Larson N, Wall M, Neumark-Sztainer D. Creating a replicable, valid crossplatform buffering technique: the sausage network buffer for measuring food and physical activity built environments. International journal of health geographics. 2012;11(1):1-9.

37. Dobesova Z, Krivka T. Walkability index in the urban planning: A case study in Olomouc city. Advances in spatial planning. 2012:179-96.

38. Bates D, Maechler M, Bolker B, Walker S. Ime4: Linear mixed-effects models using Eigen and S4. R package version 1.1-7. 2014.

39. Cerin E, Conway TL, Adams MA, Barnett A, Cain KL, Owen N, et al. Objectively-assessed neighbourhood destination accessibility and physical activity in adults from 10 countries: an analysis of moderators and perceptions as mediators. Social Science \& Medicine. 2018;211:282-93.

40. Loh VH, Veitch J, Salmon J, Cerin E, Thornton L, Mavoa S, et al. Built environment and physical activity among adolescents: the moderating effects of neighborhood safety and social support. International journal of behavioral nutrition and physical activity. 2019;16(1):1-8.

41. Rosenberger ME, Fulton JE, Buman MP, Troiano RP, Grandner MA, Buchner DM, et al. The 24-hour activity cycle: a new paradigm for physical activity. Medicine and science in sports and exercise. 2019;51(3):454.

42. Compernolle S, De Cocker K, Mackenbach JD, Van Nassau F, Lakerveld J, Cardon G, et al. Objectively measured physical environmental neighbourhood factors are not associated with accelerometerdetermined total sedentary time in adults. International Journal of Behavioral Nutrition and Physical Activity. 2017;14(1):1-6. 